\title{
Impact of prenatal cold stress on placental physiology, inflammatory response, and apoptosis in rats
}

\author{
Shuai Lian ${ }^{1}$, Jingru Guo ${ }^{1}$, Lipeng Wang ${ }^{1}$, Wenjie $\mathrm{Li}^{1}$, Jianfa Wang ${ }^{1}$, Hong Ji $^{1}$, Fanzhi \\ Kong ${ }^{1}$, Bin $\mathrm{Xu}^{1}{ }^{1}$, Shize $\mathrm{Li}^{1}$ and Huanmin Yang ${ }^{1}$ \\ ${ }^{1}$ College of Animal Science and Veterinary Medicine, Heilongjiang Bayi Agricultural University, Daqing 163319, P. R. China \\ Correspondence to: Huanmin Yang, email: byndyhm@163.com \\ Keywords: prenatal cold stress; placental; inflammatory; apoptosis; NF-KB \\ Received: September 04, $2017 \quad$ Accepted: December 04, $2017 \quad$ Published: December 14, 2017 \\ Copyright: Lian et al. This is an open-access article distributed under the terms of the Creative Commons Attribution License 3.0 \\ (CC BY 3.0), which permits unrestricted use, distribution, and reproduction in any medium, provided the original author and source \\ are credited.
}

\section{ABSTRACT}

Prenatal cold stress is one of the earliest factors affecting mammalian health, and is associated with neonatal growth retardation and immune dysfunction, thus increasing disease susceptibility. The mechanisms underlying these observations remain unclear; hence, the objective of this study was to elucidate placental responses to cold stress. 60 maternal rats were randomly allocated to either stressed $(n=30)$ or non-stressed (control, $n=30)$ treatment conditions and 30 pubs $(n=15)$ were used for the pups analysis. We found that maternal exposure to cold stress resulted in decreased body temperature, increased food intake without body weight gain, and a high level of plasma corticosterone (CORT) between gestational day (GD) 14 and GD21. In addition, gestation cold stress induced the placental expression of heat shock protein 70 (HSP70), IKBa, glucocorticoid receptor (GR), mineralocorticoid receptor

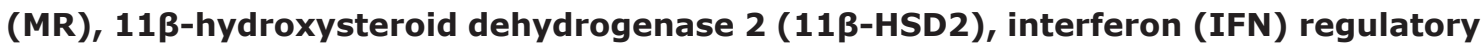
factor 3 (IRF3), Caspase-3 proteins and altered the ratio of B-cell lymphoma-extra large (Bcl-xL) to $\mathrm{Bcl}$-associated $x$ (Bax) proteins on gestational GD15, GD17, GD19, and GD21, also resulted in the production of interleukin (IL)-1 $\beta$. Next, gestational cold stress provoked a decrease in plasma GH levels of 21-day-old offspring, and the body weights of offspring were have no differences from postnatal day (PD) 1-21. Taken together, our results indicate that gestational cold stress induces placental apoptosis and the activation of NF-kB via HSP70/TLR4/NF-KB signaling pathways in the placenta, these changes may affect placental function and fetus development.

\section{INTRODUCTION}

Stress is part of normal life, experienced in biological systems, which triggers many health conditions and disorders [1]. Some stressors such as physical exercise and creative activity are usually considered healthy [2]. However, when exposure to stress is chronic, prolonged activation of the stress response may become maladaptive and have adverse consequences for the individual [3]. Cold stress include prenatal cold stress is one of these stressors, which is a major factor that can negatively affect the growth and production of all livestock species in north frigid area [4]. During this condition, energy harvesting during acute cold contributes to maintaining the body temperature. However, little is known about the effect of temperature and the feed intake changes on placental metabolism/function and that of the embryo/fetus during pregnancy cold stress, the underlying mechanisms behind these impacts remain unclear.

Stress could cause a persistent hyperactivity of the HPA axis and thus elevated glucocorticoid levels, glucocorticoids could pass through the placental barrier and reaches the fetus [5]. The placenta plays a pivotal role in the acceptance of the fetal-placental unit by the maternal immune system, and forms a barrier to maternal glucocorticoids [6]. A placental enzyme, 11 $\beta$-HSD2, normally protects the fetus from relatively high levels of maternal glucocorticoids, by inactivating approximately 
80-90\% of maternal cortisol [5]. However, this protection is not complete: one study has clearly demonstrated that maternal stress results in increased circulating cortisol in guinea pig fetuses [7], endogenous glucocorticoids bind to both glucocorticoid and mineralocorticoid receptors (GR and MR, respectively), which themselves are subject to autoregulation, and this MR/GR dual-receptor system regulates negative feedback of the hypothalamic-pituitaryadrenal (HPA) axis, which is important for homeostatic control [8]. In the fetal circulation and in particular the fetal brain, maternal cortisol can perturb the development of the fetal HPA axis during vulnerable periods by resetting the set point of the HPA axis's negative feedback mechanism, resulting in a long-lasting or even permanent change in HPA axis activity in postnatal life [9].

Heat shock protein 70 (HSP70), plays an important role in protein trafficking and the refolding of denatured proteins during stress, which can activate the TLR4 signaling pathway and subsequently induce proinflammatory cytokine production via NF- $\kappa$ B and IRF3 signal pathways $[10,11]$. But it is not clear the hypothesis behind to the effects of cold stress on HSP70 and proinflammatory cytokine production. Moreover, apoptosis can be triggered by a variety of factors, such as reactive oxidative stress [12] and inflammatory response [13]. However, research on the effects of cold stress in gestation on placental apoptosis is limited. The present study focused on the maternal response to prenatal cold stress and the data from offspring will be included in future studies.

\section{RESULTS}

\section{Body temperature, feed intake, body weight gain and gestational length}

Acute cold exposure led to significant body temperature decreases in the stressed group compared with the control group (Figure 1A). Feed intake level for 2d-6d was significantly different between the stressed and control groups (Figure $1 \mathrm{~B}, P<0.019$ ). Those rats subjected to $2-6$ days of cold stress consumed significantly more feed than those cold-stressed for one day. Body weight gain data for the pregnant rats is represented in Figure 1C. Although body weight gains in the stressed groups were numerically lower than those of the control groups, the differences did not reach statistical significance $(P>0.05)$.

\section{Maternal plasma corticosterone levels}

Stress causing activation of the HPA axis results in increased corticosterone (CORT) concentrations, driven by increased secretion of ACTH. Prenatal ACTH has been assumed to increase maternal CORT levels [14]. During gestational cold stress, we found increased corticosterone plasma levels after $1(P=0.001), 3(P=0.009)$ and 5 $(P=0.037)$ days of cold stress. At day 6 of cold stress, plasma corticosterone levels were slightly decreased, but still higher than those in the control groups, and they remained elevated until the end of gestation (Figure 1D).

\section{Expression of CD4 and CD8 antigen on $\mathrm{T}$ cells in peripheral blood}

CD4/CD8 analysis (Figure 2) revealed that the CD4/ CD8 ratio in the control group was numerically higher than those of the stressed groups, but no the difference was not significant (control $2.97 \pm 0.3653$; stressed 2.547 $\pm 0.1886,2.48 \pm 0.055,2.512 \pm 0.1853,2.485 \pm 0.1592)$.

\section{Prenatal cold stress activated the placental HSP70/TLR4/NF-кB signaling pathway}

To further investigate the prenatal stress inflammatory mechanism, we examined the HSP70/TLR4/NF-кB signaling pathway, by measuring placental HSP70, TLR4, $\mathrm{I} \kappa \mathrm{B}, \mathrm{IL}-1 \beta$, and P65 protein levels. As shown in Figure 3 , prenatal cold stress enhanced HSP70 (Figure 3A, $P<$ 0.015 ) and $\mathrm{I} \kappa \mathrm{B} \alpha$ expression (Figure $3 \mathrm{~B}, P<0.004$ ). We also demonstrated that IL-1 $\beta$ levels increased after coldstress periods of 1,3 , and 5 days (Figure $3 \mathrm{C}, P=0.000$ ), and that they decreased after 7 days of cold stress (Figure 3C, $P=0.726)$. Interestingly, placental TLR4 expression followed a similar trend after cold-stress periods of $1(P=0.001)$ and $3(P=0.000)$ days (Figure 3D), these results were possible followed the CORT levels. Our results indicate that prenatal cold stress induced activation of NF-kB via HSP70/TLR4/ $\mathrm{NF}-\kappa \mathrm{B}$ signaling pathways in the placenta.

\section{Prenatal cold stress induced expression of GR, MR, 11ß-HSD2, and IRF3 in placenta}

As shown in Figure 4, prenatal cold stress had a significant effect on grey intensity values of GR (Figure 4B) after $1(P=0.004), 3(P<0.001)$ and $7(P<0.012)$ days of cold stress, MR (Figure $4 \mathrm{C})$ after $1(P=0.000), 3(P=0.003)$ and $5(P=0.072)$ days of cold stress, and $11 \beta$-HSD2 (Figure $4 \mathrm{D}, P<0.005)$. Furthermore, we measured levels of IRF3, an interferon regulatory factor, and levels of HSP90. There was no effect on IRF3 of cold stress $1 \mathrm{~d}(P=0.486)$, as the duration of cold stress was extended, placental IRF3 expression significantly increased (Figure 4E, $P<0.013$ ). However, cold stress had no significant effect on HSP90 expression (Figure 4F, $P>0.400$ ).

\section{Bcl-xL/Bax ratio and Caspase-3 protein expression in placenta}

In addition, to determine the influence of cold stress on cell apoptosis, we examined the expression of Bcl-xL (an anti-apoptotic protein), Bax (a pro-apoptotic protein) and Caspase-3 (a key enzyme in the mitochondriadependent apoptosis pathway). As shown in Figure 5, The 
A

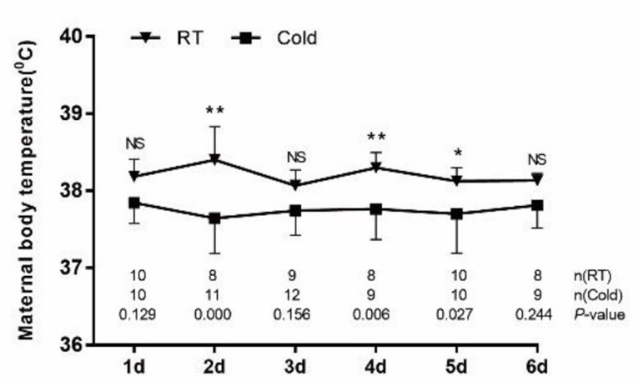

C

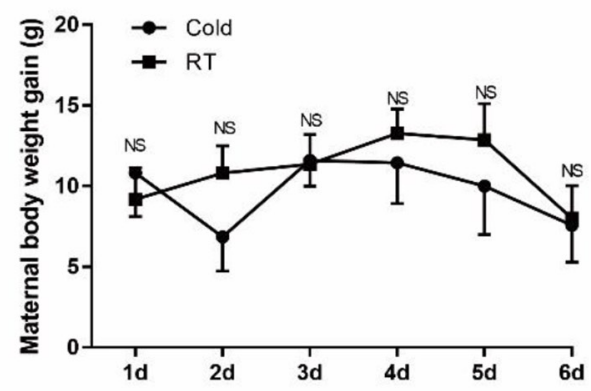

B

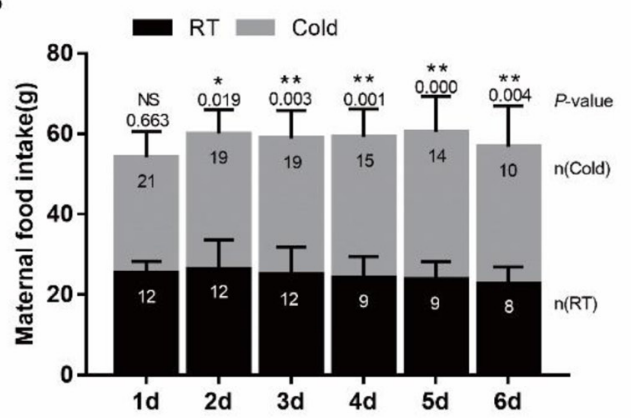

D

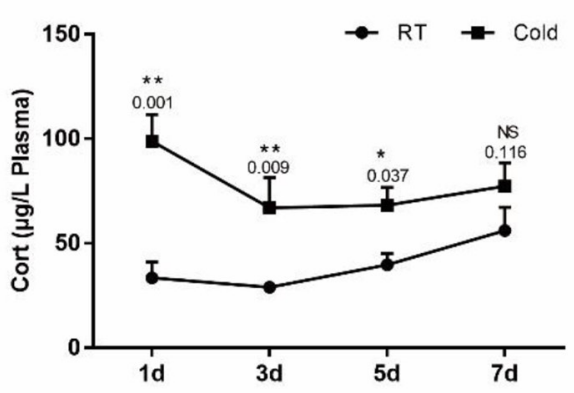

Figure 1: Impact of prenatal cold stress on maternal body temperature, food intake, and plasma CORT levels. (A) Rectal body temperature before or after cold stress. (B) Maternal food intake before or after cold stress during gestation. (C) Maternal body weight gain before or after cold stress during gestation. (D) Maternal plasma CORT levels $(\mathrm{n}=6)$. The data are shown as mean $\pm \mathrm{SD}$, statistically significant differences are indicated: ${ }^{*} P<0.05,{ }^{* *} P<0.01$.
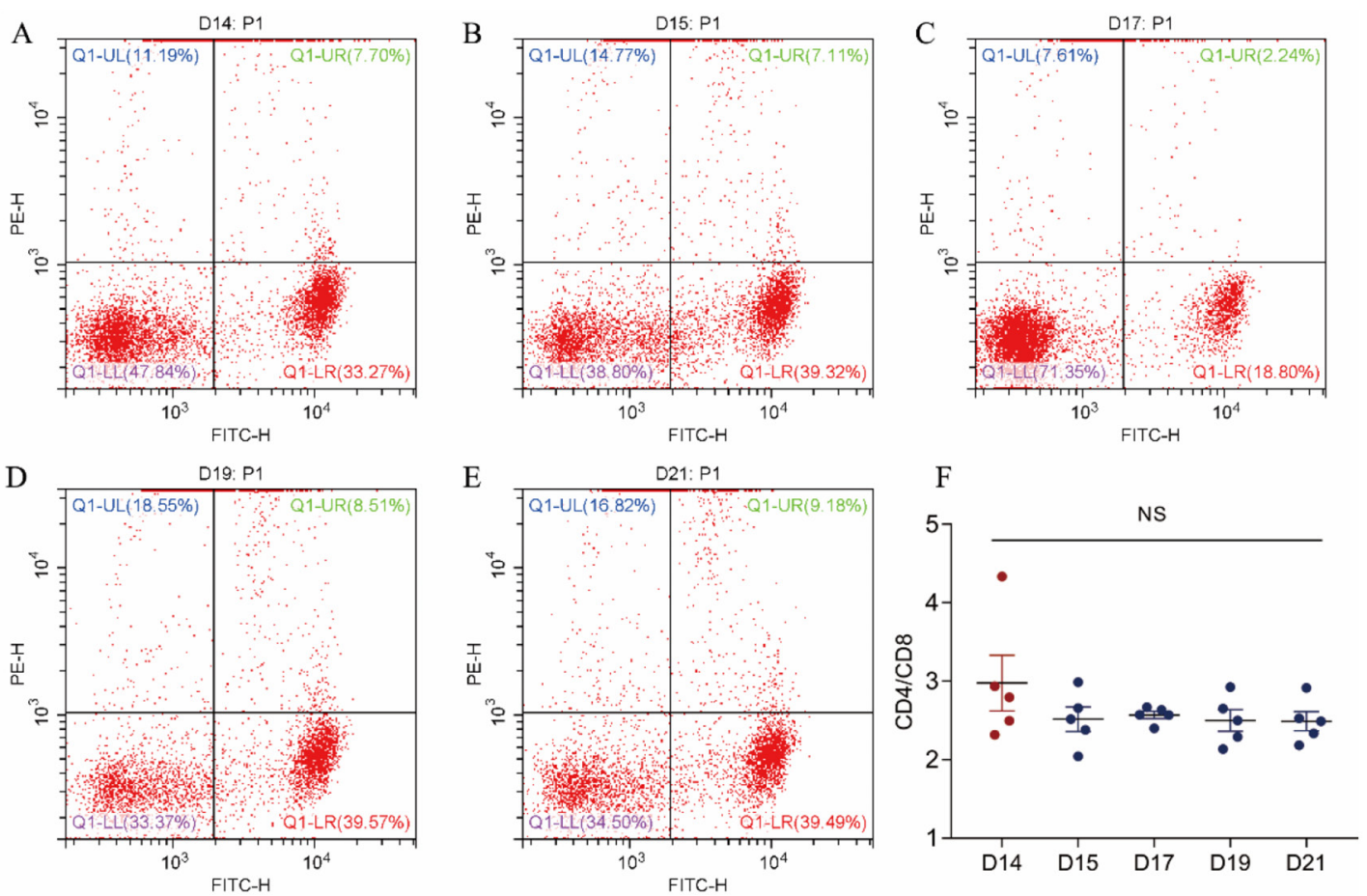

Figure 2: The effect of cold stress on the expression of CD4 and CD8 antigen on T cells in peripheral blood. (A, B, C, D, E) Representative figures from GD14 to GD21 flow cytometry analyses. (F) Analyzed data of CD4/CD8 ratio. Values are expressed as means $\pm \operatorname{SD}(n=5)$. 
$\mathrm{Bcl}-\mathrm{xL} / \mathrm{Bax}$ expression ratio reached a maximum value after cold stress of $5 \mathrm{~d}$ and $7 \mathrm{~d}$ (Figure 4B, $P=0.000$ ). In addition, Caspase- 3 protein expression was increased after cold-stress, especially in the periods of $1(P=0.003)$, $5(P=0.005)$ and 7 days $(P=0.019)$.

\section{The pups' plasma GH and body weight}

To evaluate the effect of gestational cold stress on the offspring, we weighed the pups from 1 to $21 \mathrm{~d}$ after birth and tested their plasma growth hormone levels on days 7 and 21. We demonstrated that the body weight began to appear difference from $7^{\text {th }}$ days, however, there were no significant differences between the cold stress and control groups (Figure 6B). Interestingly, gestational cold stress provoked a decrease in plasma GH levels of 21-dayold offspring (Figure 6A, $P=0.004$ ).

\section{DISCUSSION}

Stress has been demonstrated to impact virtually every organ in the body, even in the fetus. In this study, we provide evidence that prenatal cold stress exerts a significant effect on the placenta, which is associated with the HSP70/ TLR4/NF- $\kappa \mathrm{B}$ signaling pathway, a corresponding reduction in body temperature, and other factors.

Rectal temperature is considered a good indicator of core body temperature because of its close proximity to the abdominal cavity and longer equilibrium period [15]. The present study shows that prenatal cold stress induced a decrease in prenatal rats' body temperature and induced an increase in the food intake of gravid rats, without body weight gain (Figure 1C) and the fetus weights were not proportional to the feed intake (Figure 6B). These data suggest that most of the energy harvesting during acute cold mainly contributes to maintaining the body temperature, fewer flow to the placenta/fetus.

Prenatal cold stress induced a low CD4/CD8 ratio in maternal blood. CD4 and CD8 are members of the immunoglobulin superfamily. CD4 potentiates the inflammatory or humoral immune response through the actions of Th1 and Th2 cells, respectively [16], interacts with the MHC class II molecule, and is involved in T cell activation. CD8 T cells combat viral infections [17], having an antigen co-receptor that interacts with MHC class I molecules on antigen-presenting cells or epithelial cells.
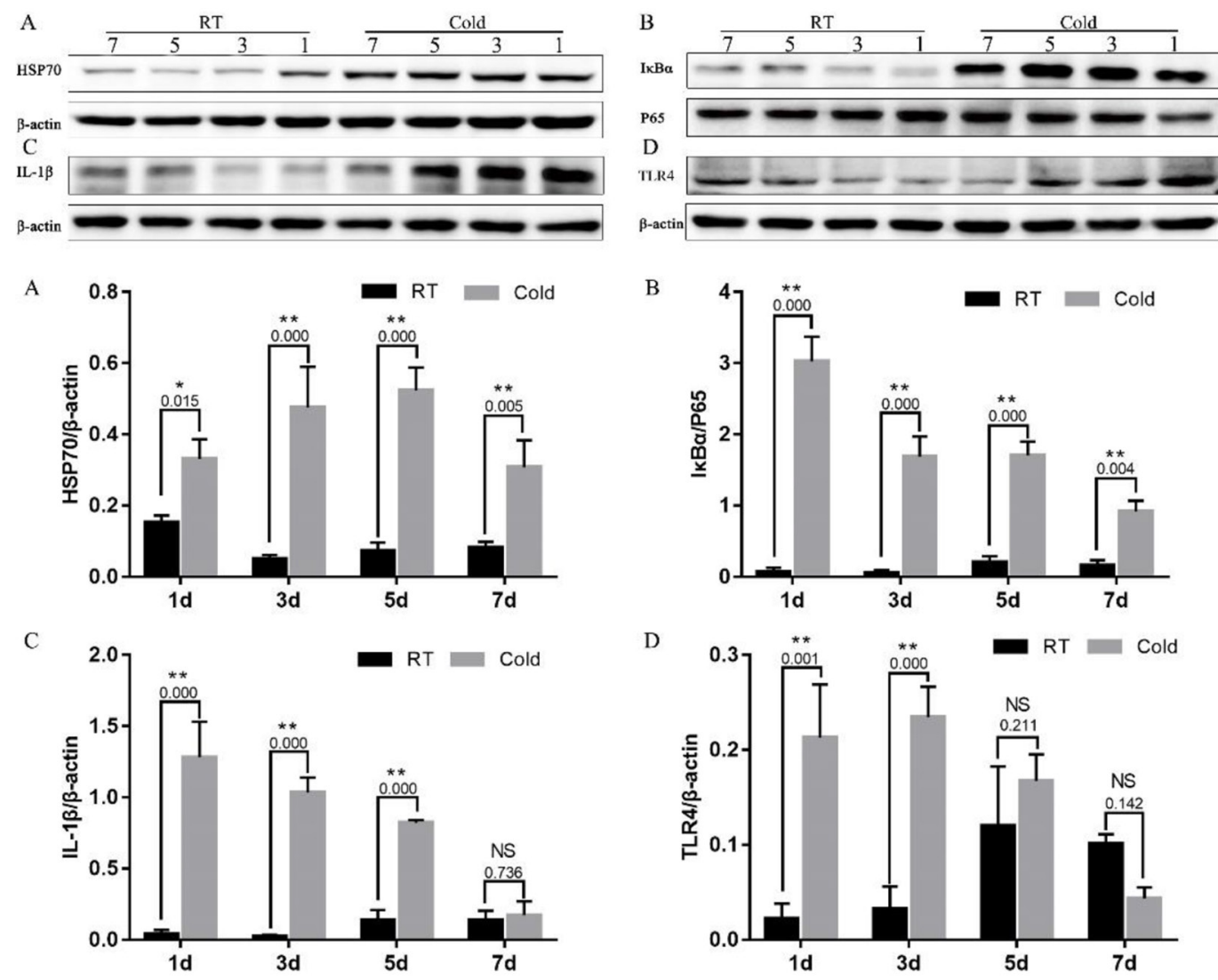

B

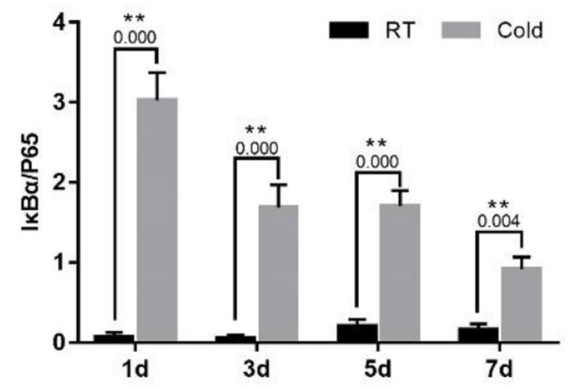

D

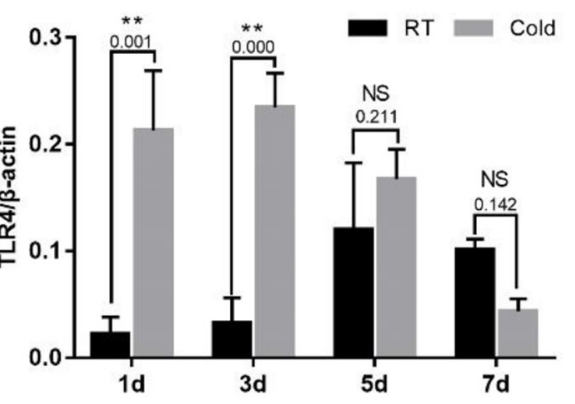

Figure 3: Impact of prenatal cold stress on the activation of the HSP70/TLR4/NF- $\mathrm{B}$ signaling pathway in placenta.

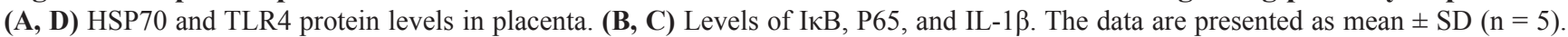
These are cropped blots, full-length blots are presented in Supplementary Figure 1. Statistically significant differences are indicated: ${ }^{*} P<$ $0.05,{ }^{* *} P<0.01$. 
A low CD4/CD8 ratio has been identified in the general population as a hallmark of immunosenescence and a surrogate of all-cause mortality; thus, the CD4/CD8 ratio may reflect the level of immune function of an individual [18].

Heat shock proteins (HSPs), implicated in a wide range of physiological functions including immunity [19], can and do exit mammalian cells, interact with cells of the immune system, and exert immunoregulatory effects [20]. In addition, it is also well known that HSP expression levels are low under normal physiological conditions, and that they rise under stressful conditions. In early pregnancy, a high risk of adverse pregnancy outcomes is associated with increased HSP70 levels [21]. Whether the expression of placenta HSP70 changes in a low-temperature environment during pregnancy has yet to be shown. We therefore determined to examine placentas from cold-stressed and non-cold-stressed dams. Our findings indicate that prenatal cold stress leads to a significant increase in placental expression of HSP70.

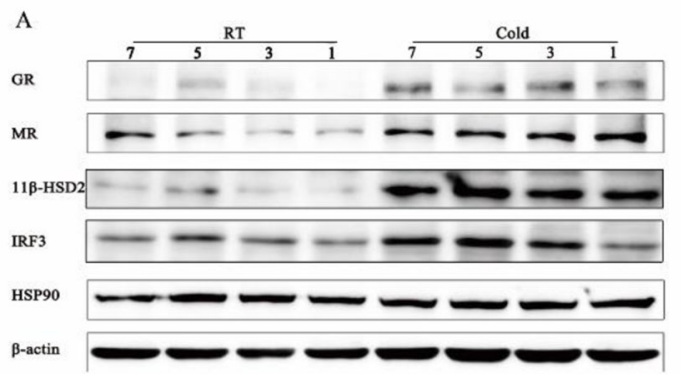

C
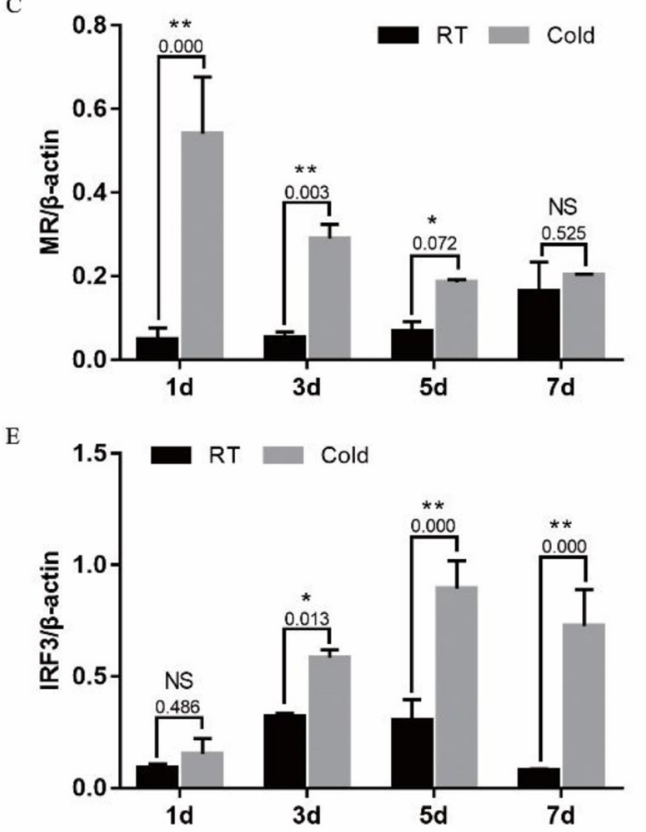

HSP70, an important endogenous ligand, can utilize CD14/TLR2/TLR4 to induce proinflammatory cytokine production via the MyD88/NF- $\kappa \mathrm{B}$ signal pathway [20]. The cytokines synthesized as a result, including TNF- $\alpha$, IL6 , IL-12, and IL-1 $\beta$, are in turn known to activate NF- $\kappa$ B [22]. Prenatal stress leads to dysbiosis, which is associated with increased IL-1 $\beta$, both in the placenta and in the brain of female fetuses [23]. In the current study, we found a significant increase in female placental expression of IL-1 $\beta$ and $\mathrm{I} \kappa \mathrm{B} \alpha$ under conditions of cold stress. NF- $\kappa \mathrm{B}$ induced I $\kappa \mathrm{B} \alpha$ expression provides a robust and dominant negative feedback loop [24]. Negative feedback control is essential in regulating NF- $\kappa \mathrm{B}$ activation, as it leads to transcriptional upregulation of the $\mathrm{I} \kappa \mathrm{B} \alpha$ and p105 genes, since both of these genes have $\mathrm{NF}-\kappa \mathrm{B}$ responsive elements in their promoters $[25,26]$. This might indicate that the enhanced $\mathrm{I} \kappa \mathrm{B} \alpha$ expression occurs through a negative feedback mechanism. We hypothesize that the HSP70/TLR4/NF-кB pathways play a key role in prenatal cold stress.
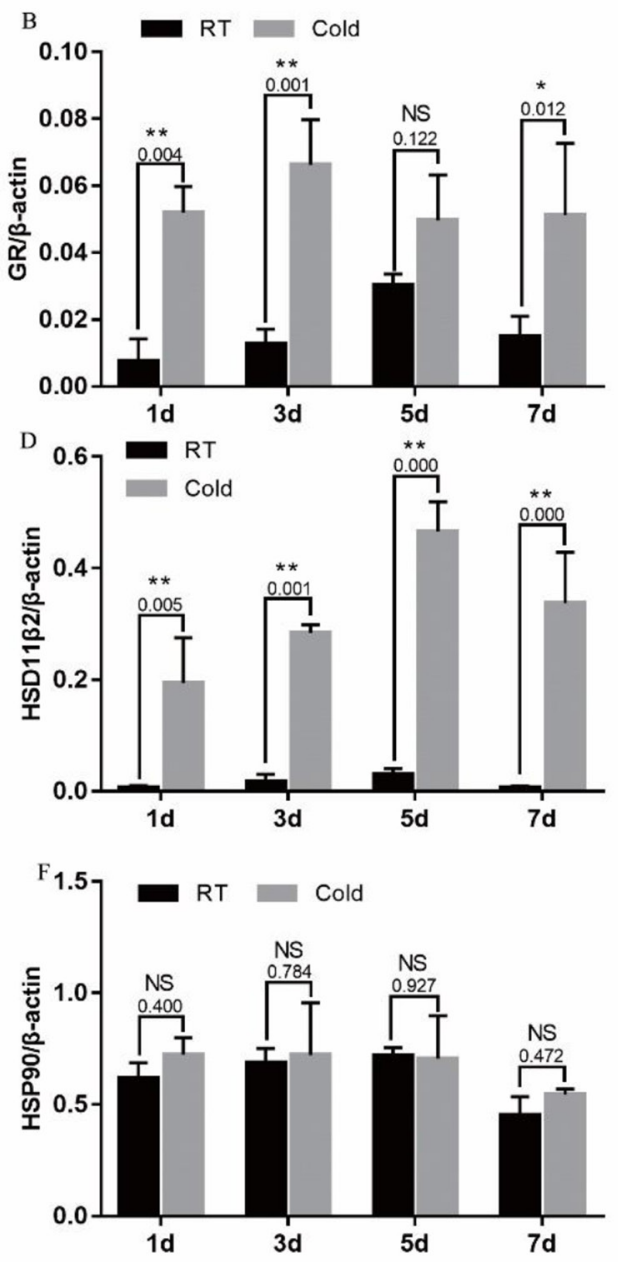

Figure 4: Effect of prenatal cold stress on the expression of GR, MR, 11ß-HSD2, and IRF3 proteins. These are cropped blots, full-length blots are presented in Supplementary Figure 2. The data are presented as mean \pm SD $(n=5)$. Statistically significant differences are indicated: ${ }^{*} P<0.05,{ }^{* *} P<0.01$. 

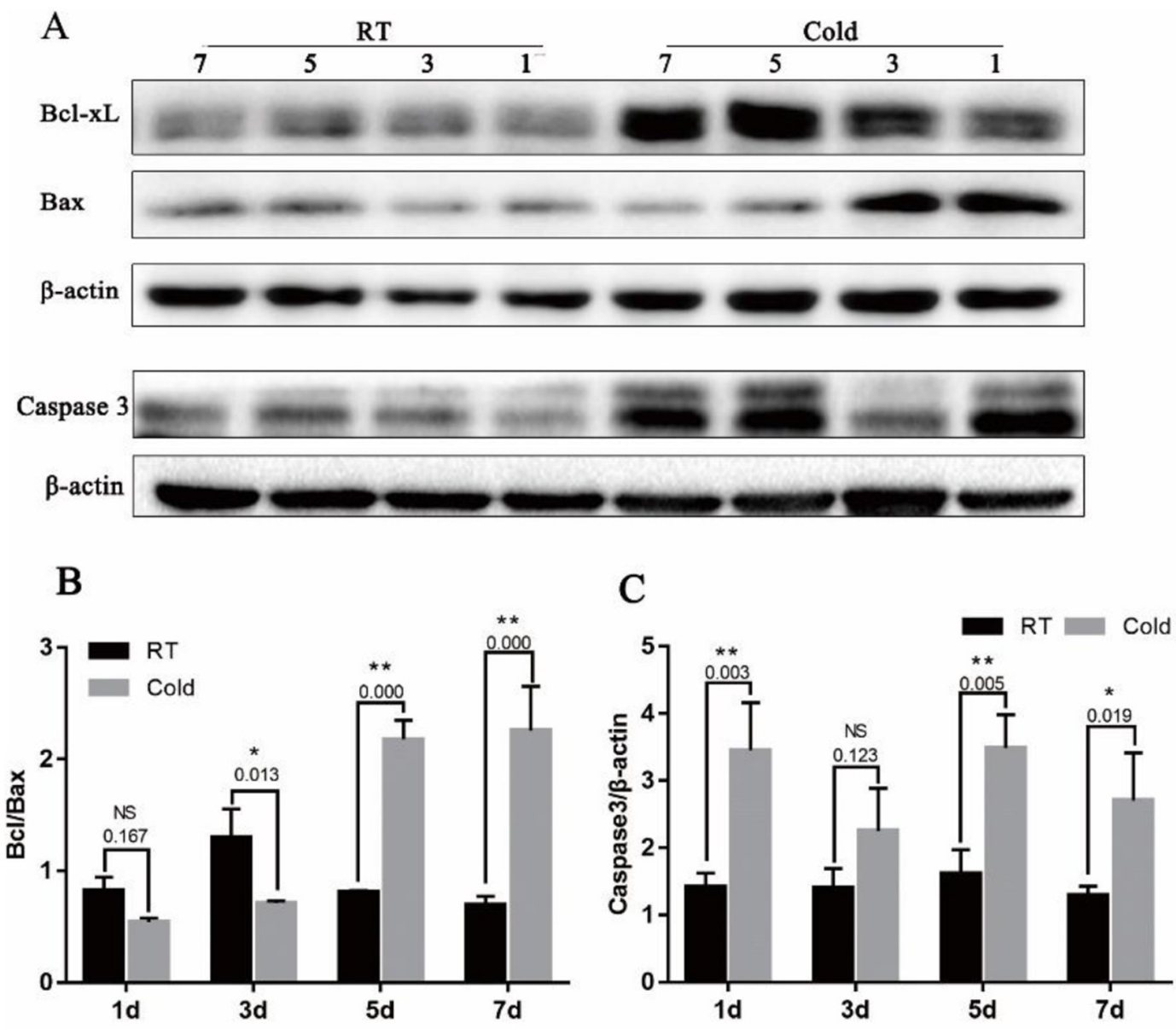

Figure 5: Effect of prenatal cold stress on the expression of Bcl-xL, Bax and Caspase3 proteins. (A) These are cropped blots, full-length blots are presented in Supplementary Figure 3. (B) Bcl-xL/Bax ratio was determined by western blot. (C) Caspase3 protein levels in placenta. The data are presented as mean $\pm \mathrm{SD}(\mathrm{n}=5)$. Statistically significant differences are indicated: ${ }^{*} P<0.01,{ }^{* *} P<0.01$.
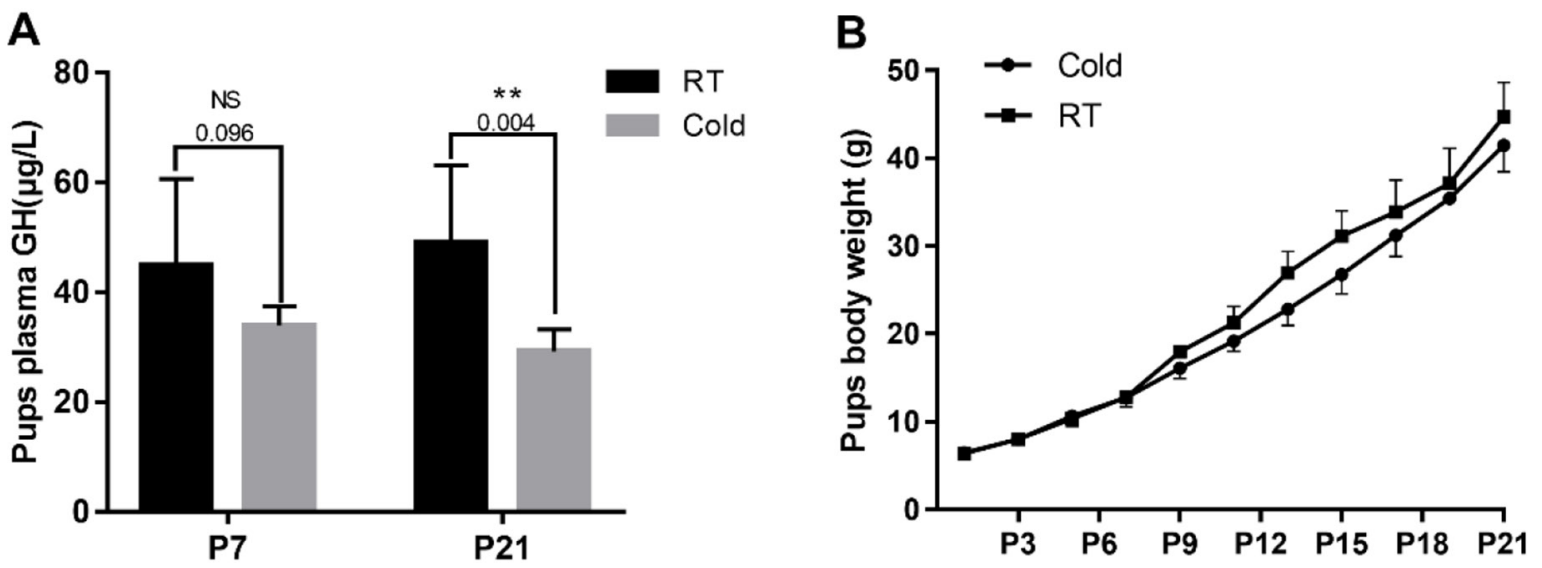

Figure 6: Prenatal cold stress decreased plasma GH levels and the body weight of offspring. (A) ELISA detection for 7 and 21 d old pups' plasma GH levels (n=6-10). (B) Pups' body weight growth curve (from postnatal days 1 to 21 ) ( $n=30)$. The data are presented as mean \pm SD. Statistically significant differences are indicated: ${ }^{*} P<0.05,{ }^{* *} P<0.01$. 
The hypothalamic-pituitary-adrenal (HPA) axis regulates the adrenal synthesis of GCs and their release into the systemic circulation. Under normal conditions, endogenous GC levels in serum display circadian variations, but under a variety of physical and psychological stresses, levels of endogenous GCs are strongly elevated, due to the influence of the hypothalamus [27]. During gestational cold stress, plasma corticosterone levels increased from day 15 of gestation, and remained high until the end of gestation [28]. In the present study, we also found high corticosterone levels during gestational cold stress, and observed an increase in placental GR and MR in response. Although GCs have been reported beneficial in promoting fetal lung maturation, overexposure to GCs may have effects, either directly or indirectly, upon the developing fetus $[29,30]$. GCs exert their effects through binding to GR, a liganddependent transcription factor [31], in both genomic and non-genomic ways, in almost every tissue in the human body. While most GCs are mediated through binding to the widely expressed GR, GCs can bind with even greater affinity to the MR [32]. In the absence of GCs, GR resides in the cytoplasm, bound to chaperone HSP90 and HSP70 [33]. The presence of a functional GR during gestation is essential for postnatal survival as well as during fetal development [29]. High corticosterone levels may induce increased expression of GR and MR during gestational cold stress. We observed that gestational cold stress induce an increase in IRF3 - a downstream effector of TLR3/4, and an essential activator of several IFN and chemokine genes. GR is able to interact with, and alter the transcriptional activity of IRF3, which binds to DNA-bound regulator-NF- $\mathrm{KB}$, utilizing p160 GRIP1 as a corepressor [34].

The availability of natural glucocorticoids in tissues is regulated by locally expressed $11 \beta$-HSD [27]. The effect of glucocorticoids, signaling through MR and GR, is often dampened by the local co-expression of the glucocorticoid

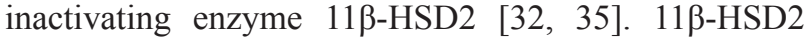
is one type of $11 \beta$-HSD that abundantly present in the placenta and protects the fetus from excessive maternal glucocorticoids. The biologically active glucocorticoid is unbound cortisol that can be converted to the inactive

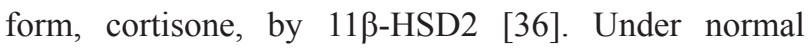
conditions, rat placental $11 \beta-\mathrm{HSD} 2$ is produced later in gestation, resulting in less loss of glucocorticoid activity [30], to allow maternal glucocorticoids to stimulate late fetal maturation. The results of this study indicate a high expression of $11 \beta-\mathrm{HSD} 2$ in placental tissue during gestational cold stress. Prenatal cold stress induced high endogenous corticosterone levels, in which case a feedback mechanism attempted to increase $11 \beta-\mathrm{HSD} 2$ expression to protect the body from damage. The effect of GCs on the regulation of placental $11 \beta-\mathrm{HSD} 2$ is still controversial: maternal betamethasone administration dramatically increased 11 $\beta$-HSD2 mRNA and protein levels in baboons [37], while high cortisol levels decrease 11ß-HSD2 enzyme activity in sheep in late pregnancy [38].

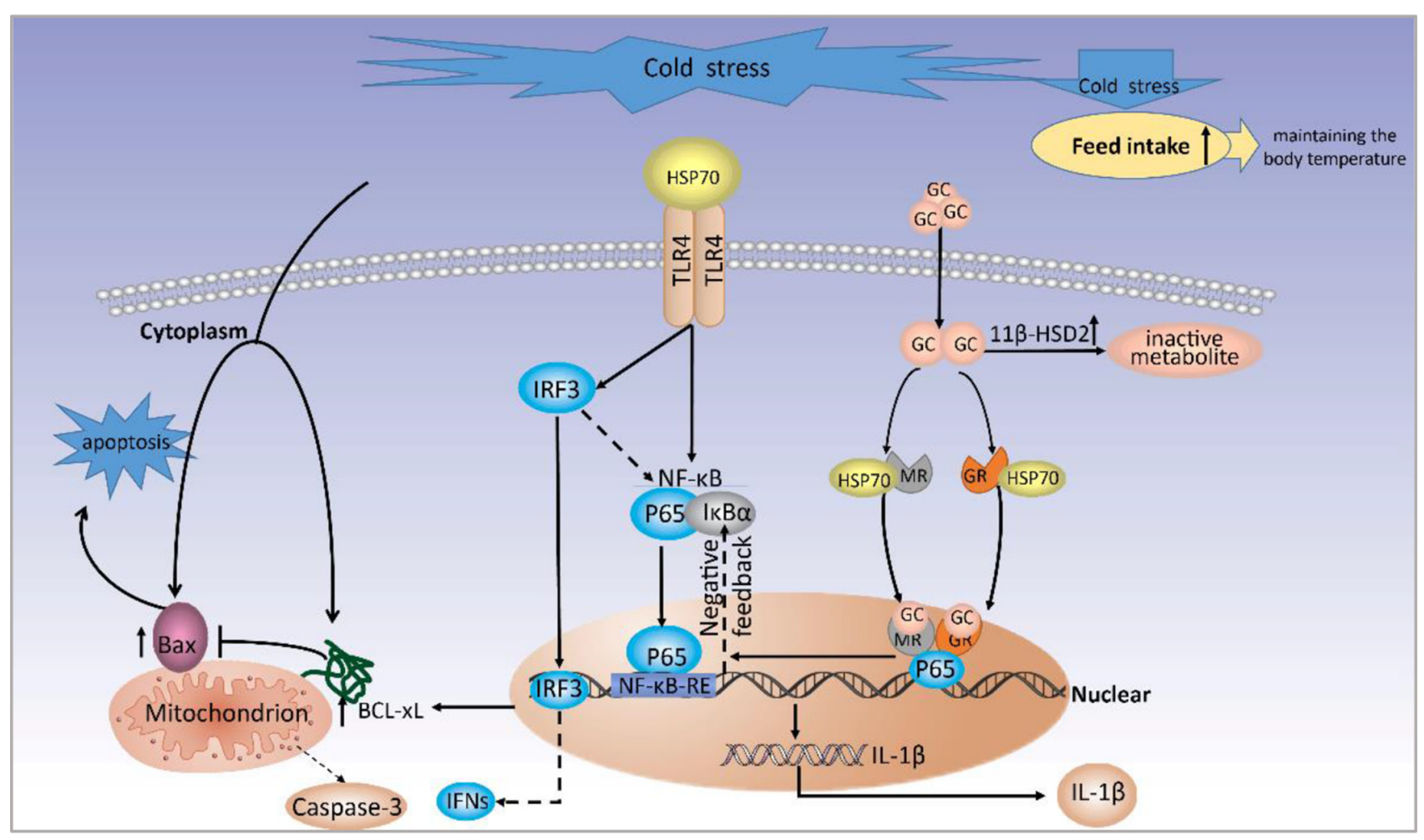

Figure 7: A proposed model for molecular mechanisms of prenatal cold stress on placental. 
Caspase 3 was the main executors of apoptosis, and the activation is a central event in apoptosis, it was a key enzyme in the mitochondria-dependent apoptosis pathway [39]. Bcl-xL (anti-apoptotic proteins) and Bax (pro-apoptotic proteins) belong to the $\mathrm{Bcl}-2$ family. Bcl-xL binds Bax at mitochondria, inhibiting Bax oligomerization, and thus, apoptosis [40]. It has been demonstrated that cold stress causes severe liver damage due to decreased levels of glutathione (GSH) and increased protein carbonylation, lipid oxidation, and abundance of intracellular reactive oxygen species (ROS), leading to oxidative stress-induced apoptosis in the liver. In our previous study, Hsp70 suppressed apoptosis of buffalo rat liver (BRL) cells by regulating the expression of $\mathrm{Bcl}-2$, cytochrome $\mathrm{C}$, and caspase 8/3 [41]. Cold stress may affect placental apoptosis. We examined the expression of the apoptosis-associated Bcl-xL, Bax and Caspase-3 protein in placentas. We observed that gestational cold stress induced high HSP70 levels, and that the ratio of Bcl-xL to Bax expression reached a maximum when cold stress lasted $5 \mathrm{~d}$ and $7 \mathrm{~d}$, and a high expression of Caspase- 3 after cold stress. The balance between the expression of the antiapoptotic gene Bcl-2 and the proapoptotic gene Bax is considered a good indicator of apoptotic activity [42]. Gestational cold stress induce placental apoptosis; however, over time, negative feedback mechanisms increase the expression of Bcl-xL and decrease that of Bax, inhibiting placental apoptosis.

In addition to the above experiments, neonates' plasma GH levels were measured at postnatal days 7 and 25 . Interestingly, gestational cold stress provoked a decrease in neonates' plasma GH levels. Abnormalities in the GHIGF axis are commonly described in growth-retarded fetuses and neonates, as well as in many adult diseases associated with low birth weight [43]. Previous research has suggested that prenatal stress-induced increases in maternal glucocorticoids impairs the development of the adult offspring's glucocorticoid response [44]. Acute stress inhibits GH secretion in rats [45]. Glucocorticoids can cross the placenta, weaken the HPA axis, which mediates the bodily responses to stress, and reduce pituitary GH secretion, affecting fetal development.

In summary, the present study demonstrated that prenatal cold stress in rats induces inflammation and apoptosis in the placenta, and results in low plasma $\mathrm{GH}$ levels, and the role of prenatal cold stress on placental was demonstrated (Figure 7). We will further examine the influence of gestational cold stress on offspring in a future study, providing a better understanding of the role of prenatal cold stress in the development of offspring.

\section{MATERIALS AND METHODS}

\section{Animals and ethics}

30 male $(280 \pm 20 \mathrm{~g})$ and 60 female $(230 \pm 20 \mathrm{~g})$ specific pathogen free (SPF) Wistar rats were obtained from the Experimental Animal Center, Qiqihar Medical University, and kept in a climatic chamber at an ambient temperature of $22 \pm 2{ }^{\circ} \mathrm{C}$ and $40 \%$ relative humidity, under a 12/12 h light/dark cycle (light on from 8:00 a.m. to 8:00 p.m.), and with free access to food and water. Procedures involving animals were approved by the Animal Care Committee of the Heilongjiang Bayi Agricultural University (Daqing, China), and all the experiments protocols were performed in accordance with relevant guidelines and regulations of the Heilongjiang Bayi Agricultural University (Daqing, China). Animals were allowed to acclimate for at least one week before being subjected to experimental conditions.

\section{Prenatal stress and sample collection}

Vaginal smears were taken daily from female rats to determine the phase of the estrus cycle prior to mating. On the day of proestrus, two females were placed with one male rat at 8:00 p.m. and vaginal smears were checked for the presence of sperm before 8:00 a.m. the next morning. The day on which a vaginal smear with sperm cells was obtained was designated as gestational day (GD) 0 [46]. Pregnant rats were individually housed in polypropylene cages $(37.5 \times 27.3 \times 16.5 \mathrm{~cm})$ at a temperature of $22 \pm 2{ }^{\circ} \mathrm{C}$ for GD0-14. At GD14, they were randomly allocated to either stressed $(n=30)$ or non-stressed (control, $n=30)$ treatment conditions. According to the number of stress days, stressed and control groups were further divided into 1d (GD15), 3d (GD17), 5d (GD19), 7d (GD21), and Term Delivery (TD) groups ( $\mathrm{n}=6$ in each), TD groups were for the pups analysis. Non-stressed pregnant rats were performed at 22 $\pm 2{ }^{\circ} \mathrm{C}$. Stressed pregnant rats were exposed to cold stress, performed at $4{ }^{\circ} \mathrm{C}$ in a climatic chamber. Pregnant rats were anesthetized on GD15, GD17, GD19, and GD21 with pentobarbital sodium and euthanized for sample collection. After the parturition of TD groups, the stressed as same as the non-stressed groups were transferred to a climatic chamber at a temperature of $22 \pm 2{ }^{\circ} \mathrm{C}$ for the pups analysis. Blood samples were collected from the anesthetized pregnant rats on GD15, GD17, GD19, and GD21. Fetus-placentas were obtained from the mid-region of each uterine horn (total of six per mother). Labyrinth placental zones which was the major site of maternal-fetal transfer and undergoes rapid growth over the final week of gestation to support the growing fetus were separated [47], and the samples of per mother were mixed. On postnatal days (PD) 7 and 21, offspring of each group were anesthetized with pentobarbital sodium and euthanized. Blood samples were collected from the offspring. All samples were frozen in liquid nitrogen and stored at $-80{ }^{\circ} \mathrm{C}$ for subsequent examination.

\section{Body weight, feed intake and rectal temperature}

Between GD14 and GD21, maternal body weight, feed intake, and rectal temperature were taken daily. The 
body weights of offspring were also taken daily from PD1-21. The total weight gain was calculated at the end of the experimental period.

\section{Maternal plasma CORT and neonatal GH levels}

The levels of growth hormone (GH) and corticosterone (CORT) in plasma and amniotic fluids were detected using ELISA kits according to the manufacturer's protocol (both R\&D Systems, USA).

\section{Flow cytometry analysis of blood CD4, CD8}

After stressed 1d, 3d, 5d and 7d, $100 \mu \mathrm{l}$ samples of anti-coagulated whole blood were collected. The whole blood was then stained with FITC anti-rat CD4 (\#201505, Biolegend, USA) and PE anti-rat CD8a (\#200608, Biolegend, USA) for 15-20 min, while shielded from light at room temperature of $22 \pm 2{ }^{\circ} \mathrm{C}$. After incubation, the samples were fixed with $2 \mathrm{ml} 1 \mathrm{X}$ red blood cell (RBC) lysis buffer (\#420301, Biolegend, USA) for $10 \mathrm{~min}$, while shielded from light at room temperature, before being centrifuged at $350 \mathrm{~g}$ for $5 \mathrm{~min}$. The resulting supernatant was discarded, and cells were washed and resuspended in at least $2 \mathrm{ml}$ of cell-staining buffer for flow cytometry analysis (Beckman CytoFLEX, USA).

\section{Protein extraction and western blot}

Tissue samples were homogenized in RIPA buffer (\#P0013B, Beyotime, China), and their protein concentration was determined using a BCA protein assay (\#P0010, Beyotime, China), then separated by SDSPAGE and transferred onto PVDF membranes $(0.22 \mu \mathrm{m}$, $0.45 \mu \mathrm{m}$, Millipore, Germany). PVDF membranes were blocked in TBST (Tris-buffered with $0.1 \%$ Tween-20) with $5 \%$ skim milk, and the membrane was incubated with primary antibodies at $4{ }^{\circ} \mathrm{C}$ overnight. Signals were detected using the ECL kit (\#P0018, Beyotime, China). Blots were imaged using the ChemiDoc XRS (Bio-Rad) and analysis of western blot images was performed using ImageJ software (http://imagej.nih.gov/ij/). Beta-actin was used as the reference protein.

HSP70 (1:1000, \#ab47455) and Bcl-xL (1:10000, \#ab178844) antibodies were purchased from Abcam (Amyjet Scientific Inc, UK). Bax (1:3000, \#50599-2-lg), $\beta$-actin $(1: 15000, \# 60008-1-\lg )$, P65 (1:1000, \#107451-AP), GR (1:2000, \#24050-1-AP), IL-1 $\beta$ (1:1000, \#16806-1-AP), MR (1:2000, \#21854-1-AP), 11ß-HSD2 (1:500, \#14192-1-AP), TLR4 (1:2000, \#19811-1-AP), IRF3(1:2500, \#11312-1-AP), IкB $\alpha$ (1:2500, \#102681-AP), Caspase-3 (1:500, \#19677-1-AP) and HSP90 (1:5000, \#13171-1-AP) antibodies were purchased from Proteintech (USA). Secondary antibodies were labeled with horseradish peroxidase goat anti-mouse $\operatorname{IgG}(1: 8000$, \# SA00001-1, Proteintech, USA) and goat anti-rabbit IgG (1:8000, \#SA00001-2, Proteintech, USA).

\section{Statistical analysis}

Data were expressed as mean \pm standard deviation from the mean (SD). Two-way ANOVA for repeated measures was used to analyze data from maternal body temperature, food intake, body weight gain, plasma CORT levels, pubs' plasma GH levels and pubs body weight. For placental western blot parameters, comparison between groups was performed using Student's t-tests. The data were analysed using GraphPad Prism Software (La Jolla, CA, USA). Statistical significance was declared at $P<0.05$.

\section{Author contributions}

All authors reviewed the manuscript. H.Y., S.L. and J.G. designed the experiments. S.L., L.W. and W.L. performed the experiments. S.L. performed the data analysis and wrote the manuscript. J.W., H.J. and S.L. revised the manuscript. W.G., F.K. and B.X. helped in sample collection and processing.

\section{ACKNOWLEDGMENTS}

The authors thank the staff and students of the animal stress biology lab for animal care and data collection.

\section{CONFLICTS OF INTEREST}

The authors declare no competing financial interest.

\section{GRANT SUPPORT}

This work was supported by the National Natural Science Foundation of China (No.31672513 and No.31772695), and the Foundation postgraduate innovation project of Heilongjiang Bayi Agricultural University (No.YJSCX2016-Z02).

\section{REFERENCES}

1. Wang X, Zhao T, Qiu Y, Su M, Jiang T, Zhou M, Zhao A, Jia W. Metabonomics approach to understanding acute and chronic stress in rat models. J Proteome Res. 2009; 8: 25118. https://doi.org/10.1021/pr801086k.

2. Bergamini MR, Kabadayan F, Bernardi MM, Suffredini IB, Ciaramicoli MT, Kodama RM, Saraceni CH. Stress and its role in the dentin hypersensitivity in rats. Arch Oral Biol. 2016; 73: 151-60. https://doi.org/10.1016/j. archoralbio.2016.10.007.

3. Hylander BL, Repasky EA. Thermoneutrality, mice, and cancer: a heated opinion. Trends Cancer. 2016; 2: 166-75.

4. Xu Q, Wang YC, Liu R, Brito LF, Kang L, Yu Y, Wang DS, Wu HJ, Liu A. Differential gene expression in the peripheral blood of Chinese Sanhe cattle exposed to severe 
cold stress. Genet Mol Res. 2017. https://doi.org/10.4238/ gmr16029593.

5. Rakers F, Rupprecht S, Dreiling M, Bergmeier C, Witte OW, Schwab M. Transfer of maternal psychosocial stress to the fetus. Neurosci Biobehav Rev. 2017. https://doi. org/10.1016/j.neubiorev.2017.02.019.

6. Jensen Pena C, Monk C, Champagne FA. Epigenetic effects of prenatal stress on 11beta-hydroxysteroid dehydrogenase- 2 in the placenta and fetal brain. PLoS One. 2012; 7: e39791. https://doi.org/10.1371/journal. pone.0039791.

7. Dauprat P, Monin G, Dalle M, Delost P. The effects of psychosomatic stress at the end of pregnancy on maternal and fetal plasma cortisol levels and liver glycogen in guinea-pigs. Reprod Nutr Dev. 1984; 24: 45-51.

8. Zhou J, Li L, Tang S, Cao X, Li Z, Li W, Li C, Zhang X. Effects of serotonin depletion on the hippocampal GR/MR and BDNF expression during the stress adaptation. Behav Brain Res. 2008; 195: 129-38. https://doi.org/10.1016/j. bbr.2008.06.009.

9. Cottrell EC, Seckl JR. Prenatal stress, glucocorticoids and the programming of adult disease. Front Behav Neurosci. 2009; 3: 19. https://doi.org/10.3389/neuro.08.019.2009.

10. Qi M, Zheng L, Qi Y, Han X, Xu Y, Xu L, Yin L, Wang C, Zhao Y, Sun H, Liu K, Peng J. Dioscin attenuates renal ischemia/reperfusion injury by inhibiting the TLR4/MyD88 signaling pathway via up-regulation of HSP70. Pharmacol Res. 2015; 100: 341-52. https://doi.org/10.1016/j. phrs.2015.08.025.

11. Zhao H, Perez JS, Lu K, George AJ, Ma D. Role of Tolllike receptor-4 in renal graft ischemia-reperfusion injury. Am J Physiol Renal Physiol. 2014; 306: F801-11. https:// doi.org/10.1152/ajprenal.00469.2013.

12. Ryter SW, Kim HP, Hoetzel A, Park JW, Nakahira K, Wang $\mathrm{X}$, Choi AM. Mechanisms of cell death in oxidative stress. Antioxid Redox Signal. 2007; 9: 49.

13. Fernandes-Alnemri T, Yu JW, Datta P, Wu J, Alnemri ES. AIM2 activates the inflammasome and cell death in response to cytoplasmic DNA. Nature. 2009; 458: 509-13. https://doi.org/10.1038/nature07710.

14. Welberg LA, Seck1 JR. Prenatal stress, glucocorticoids and the programming of the brain. J Neuroendocrinol. 2001; 13: 113-28.

15. Aarif O, Mahapatra PS, Yatoo MA, Dar SA. Impact of cold Stress on physiological, hormonal and immune status in male and female broad breasted White Turkeys. J Stress Physiol Biochem. 2013.

16. Szmeja Z. Recenzja podręcznika pt. „CT Teaching Manual. A systematic approach to CT reading". Otolaryngol Pol. 2008; 62: 117. https://doi.org/10.1016/ s0030-6657(08)70226-9.

17. Schenkel JM, Fraser KA, Beura LK, Pauken KE, Vezys V, Masopust D. Resident memory CD8 T cells trigger protective innate and adaptive immune responses. Science. 2014; 346: 98-101. https://doi.org/10.1126/ science. 1254536.

18. Serrano-Villar S, Perez-Elias MJ, Dronda F, Casado JL, Moreno A, Royuela A, Perez-Molina JA, Sainz T, Navas E, Hermida JM, Quereda C, Moreno S. Increased risk of serious non-AIDS-related events in HIV-infected subjects on antiretroviral therapy associated with a low CD4/CD8 ratio. PLoS One. 2014; 9: e85798. https://doi.org/10.1371/ journal.pone.0085798.

19. Brenu EW, Staines DR, Tajouri L, Huth T, Ashton KJ, Marshall-Gradisnik SM. Heat shock proteins and regulatory T cells. Autoimmune Dis. 2013; 2013: 813256. https://doi. org/10.1155/2013/813256.

20. Asea A, Rehli M, Kabingu E, Boch JA, Bare O, Auron PE, Stevenson MA, Calderwood SK. Novel signal transduction pathway utilized by extracellular HSP70: role of toll-like receptor (TLR) 2 and TLR4. J Biol Chem. 2002; 277: 15028-34. https://doi.org/10.1074/jbc.M200497200.

21. Tan H, Xu Y, Xu J, Wang F, Nie S, Yang M, Yuan J, Tanguay RM, Wu T. Association of increased heat shock protein 70 levels in the lymphocyte with high risk of adverse pregnancy outcomes in early pregnancy: a nested case-control study. Cell Stress Chaperones. 2007; 12: 230-6.

22. Blackwell TS, Christman JW. The role of nuclear factorkappa B in cytokine gene regulation. Am J Respir Cell Mol Biol. 1997; 17: 3-9. https://doi.org/10.1165/ ajrcmb.17.1.f132.

23. Gur TL, Shay L, Vadodkar Palkar A, Fisher S, Varaljay VA, Dowd S, Bailey MT. Prenatal stress affects placental cytokines and neurotrophins, commensal microbes, and anxiety-like behavior in adult female offspring abbreviated title: prenatal stress and microbiome. Brain Behav Immun. 2016. https://doi.org/10.1016/j.bbi.2016.12.021.

24. Ghosh S, Hayden MS. New regulators of NF-kappaB in inflammation. Nat Rev Immunol. 2008; 8: 837-48. https:// doi.org/10.1038/nri2423.

25. Ito CY, Kazantsev AG, Baldwin AS Jr. Three NF-kappa $\mathrm{B}$ sites in the I kappa B-alpha promoter are required for induction of gene expression by TNF alpha. Nucleic Acids Res. 1994; 22: 3787-92.

26. Cogswell PC, Scheinman RI, Baldwin AS Jr. Promoter of the human NF-kappa B p50/p105 gene. Regulation by NF-kappa B subunits and by c-REL. J Immunol. 1993; 150: 2794-804.

27. Clark AR, Belvisi MG. Maps and legends: the quest for dissociated ligands of the glucocorticoid receptor. Pharmacol Ther. 2012; 134: 54-67. https://doi.org/10.1016/j. pharmthera.2011.12.004.

28. Piquer B, Fonseca JL, Lara HE. Gestational stress, placental norepinephrine transporter and offspring fertility. Reproduction. 2017; 153: 147-55. https://doi.org/10.1530/ rep-16-0312. 
29. Kadmiel M, Cidlowski JA. Glucocorticoid receptor signaling in health and disease. Trends Pharmacol Sci. 2013; 34: 518-30. https://doi.org/10.1016/j.tips.2013.07.003.

30. Harris A, Seckl J. Glucocorticoids, prenatal stress and the programming of disease. Horm Behav. 2011; 59: 279-89. https://doi.org/10.1016/j.yhbeh.2010.06.007.

31. Nicolaides NC, Galata $Z$, Kino $T$, Chrousos GP, Charmandari E. The human glucocorticoid receptor: molecular basis of biologic function. Steroids. 2010; 75: 1-12. https://doi.org/10.1016/j.steroids.2009.09.002.

32. Solano ME, Holmes MC, Mittelstadt PR, Chapman $\mathrm{KE}$, Tolosa E. Antenatal endogenous and exogenous glucocorticoids and their impact on immune ontogeny and long-term immunity. Semin Immunopathol. 2016. https:// doi.org/10.1007/s00281-016-0575-z.

33. Vardas K, Ilia S, Sertedaki A, Charmandari E, Briassouli E, Goukos D, Apostolou K, Psarra K, Botoula E, Tsagarakis S, Magira E, Routsi C, Stratakis CA, et al. Increased glucocorticoid receptor expression in sepsis is related to heat shock proteins, cytokines, and cortisol and is associated with increased mortality. Intensive Care Med Exp. 2017; 5: 10. https://doi.org/10.1186/s40635-017-0123-8.

34. Reily MM, Pantoja C, Hu X, Chinenov Y, Rogatsky I. The GRIP1: IRF3 interaction as a target for glucocorticoid receptor-mediated immunosuppression. EMBO J. 2006; 25: 108-17. https://doi.org/10.1038/sj.emboj.7600919.

35. Waddell BJ, Benediktsson R, Brown RW, Seckl JR. Tissue-specific messenger ribonucleic acid expression of 11beta-hydroxysteroid dehydrogenase types 1 and 2 and the glucocorticoid receptor within rat placenta suggests exquisite local control of glucocorticoid action. Endocrinology. 1998; 139: 1517-23. https://doi.org/10.1210/ endo.139.4.5900.

36. Moisiadis VG, Matthews SG. Glucocorticoids and fetal programming part 2: mechanisms. Nat Rev Endocrinol. 2014; 10: 403-11. https://doi.org/10.1038/nrendo.2014.74.

37. Ma XH, Wu WX, Nathanielsz PW. Gestation-related and betamethasone-induced changes in $11 \beta$-hydroxysteroid dehydrogenase types 1 and 2 in the baboon placenta. Am J Obstet Gynecol. 2003; 188: 13-21. https://doi.org/10.1067/ mob.2003.62.

38. Clarke KA, Ward JW, Forhead AJ, Giussani DA, Fowden AL. Regulation of 11 beta-hydroxysteroid dehydrogenase type 2 activity in ovine placenta by fetal cortisol. J Endocrinol. 2002; 172: 527-34.

39. Wu R, Tang $\mathrm{S}$, Wang $\mathrm{M}, \mathrm{Xu} \mathrm{X}$, Yao C, Wang $\mathrm{S}$. MicroRNA-497 induces apoptosis and suppresses proliferation via the $\mathrm{Bcl}-2 / \mathrm{Bax}$-caspase9-caspase3 pathway and cyclin D2 protein in HUVECs. PLoS One. 2016; 11: e0167052. https://doi.org/10.1371/journal. pone. 0167052 .

40. Ding J, Mooers BH, Zhang Z, Kale J, Falcone D, McNichol J, Huang B, Zhang XC, Xing C, Andrews DW, Lin J. After embedding in membranes antiapoptotic Bcl-XL protein binds both Bcl-2 homology region 3 and helix 1 of proapoptotic Bax protein to inhibit apoptotic mitochondrial permeabilization. J Biol Chem. 2014; 289: 11873-96. https://doi.org/10.1074/jbc.M114.552562.

41. Kong F, Wang H, Guo J, Peng M, Ji H, Yang H, Liu B, Wang J, Zhang X, Li S. Hsp70 suppresses apoptosis of BRL cells by regulating the expression of $\mathrm{Bcl}-2$, cytochrome $\mathrm{C}$, and caspase 8/3. In Vitro Cell Dev Biol Anim. 2016; 52: 568-75. https://doi.org/10.1007/s11626-016-0005-5.

42. Martinez-Arribas F, Nunez-Villar MJ, Lucas AR, Sanchez J, Tejerina A, Schneider J. Immunofluorometric study of Bcl-2 and Bax expression in clinical fresh tumor samples from breast cancer patients. Anticancer Res. 2003; 23: 565-8.

43. Mairesse J, Lesage J, Breton C, Breant B, Hahn T, Darnaudery M, Dickson SL, Seckl J, Blondeau B, Vieau D, Maccari S, Viltart O. Maternal stress alters endocrine function of the feto-placental unit in rats. Am J Physiol Endocrinol Metab. 2007; 292: E1526-33. https://doi. org/10.1152/ajpendo.00574.2006.

44. Barbazanges A, Piazza PV, Le Moal M, Maccari S. Maternal glucocorticoid secretion mediates long-term effects of prenatal stress. J Neurosci. 1996; 16: 3943-9.

45. Fujikawa T, Soya H, Fukuoka H, Alam KS, Yoshizato H, Mcewen BS, Nakashima K. A biphasic regulation of receptor mRNA expressions for growth hormone, glucocorticoid and mineralocorticoid in the rat dentate gyrus during acute stress. Brain Res. 2000; 874: 186.

46. Liu Y, Xu D, Feng J, Kou H, Liang G, Yu H, He X, Zhang B, Chen L, Magdalou J, Wang H. Fetal rat metabonome alteration by prenatal caffeine ingestion probably due to the increased circulatory glucocorticoid level and altered peripheral glucose and lipid metabolic pathways. Toxicol Appl Pharmacol. 2012; 262: 205-16. https://doi. org/10.1016/j.taap.2012.05.002.

47. Jones ML, Mark PJ, Mori TA, Keelan JA, Waddell BJ. Maternal dietary omega-3 fatty acid supplementation reduces placental oxidative stress and increases fetal and placental growth in the rat. Biol Reprod. 2013; 88: 37. https://doi.org/10.1095/biolreprod.112.103754. 